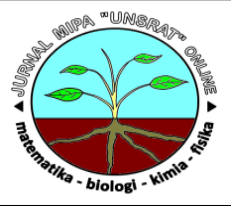

\title{
Pembuatan Aplikasi Prakiraan Cuaca Menggunakan Bahasa Pemrograman Visual Basic
}

\author{
Ricky Daniel Aror'), Hesky Stevy Kolibu2), Guntur Pasau2)
}

1) Badan Meteorologi Klimatologi dan Geofisika

2) Jurusan Fisika, Fakultas MIPA, Universitas Sam Ratulangi

\begin{tabular}{l}
\hline K A T A K U N C I \\
\hline Prakiraan cuaca \\
Visual Basic
\end{tabular}

A B S T R A K

K E Y W O R D S

Weather forecast

Visual Basic
Metode prakiraan cuaca yang selama ini hanya dilakukan secara manual dengan melihat parameter-parameter cuaca yang ada, sehingga dibuat suatu program aplikasi komputer untuk memudahkan para prakirawan dalam menganalisa dan membuat prakiraan cuaca. Software pembuat program, Visual Basic 6.0 dimanfaatkan dalam pembuatan program aplikasi prakiraan cuaca ini. Tersedianya form pada Visual Basic yang mudah untuk dimodifikasi, memudahkan pengguna untuk mengatur tampilan aplikasi kemudian dijalankan dengan menggunakan kode (script) sebagai perintah.

Hasilnya berupa sebuah program aplikasi prakiraan cuaca berekstensi *.exe yang dapat dijalankan pada perangkat komputer. Dengan menggunakan aplikasi prakiraan cuaca ini para prakirawan akan lebih mudah menganalisis dan mengoreksi langsung pada aplikasi ini jika ada kesalahan dan waktu yang dibutuhkan relatif lebih cepat (efisien). A B S T R A C T

Methods of weather forecasting have only done manually by using provided weather parameters, so there is a need to build a computer application program in facilitating the forecasters to analyze and make forecasts. Maker software program called Visual Basic 6.0 application program was utilized in building this forecasts application. Availability of the Visual Basic form that is easy to modify allows users to adjust the display and then run the application using the code (script) as a command.

The result is a weather forecast application program with extension *.exe that can be run on the computer. By using this application the weather forecasters will be easier to analyze and correct it directly on the application if there is an error and the time it takes relatively more quickly (efficiently).

AVAILABLE ONLINE

08 November 2013

*Corresponding author: Jurusan Kimia FMIPA UNSRAT, Jl. Kampus Unsrat, Manado, Indonesia 95115; Email address: ricky.aror@bmkg.go.id 


\section{Pendahuluan}

Aktivitas manusia dalam banyak hal sangat dipengaruhi oleh cuaca. Berbagai upaya terus dilakukan guna mendapatkan informasi cuaca yang lebih baik dan akurat. Para peneliti di bidang meteorologi berusaha untuk mengembangkan metode-metode prakiraan cuaca. Berdasar pada ilmu alam khususya ilmu cuaca (Meteorologi), para peneliti merumuskan kriteria-kriteria cuaca yang digunakan dalam prakiraan cuaca. Parameter yang dijadikan acuan antara lain seperti tekanan udara, pola sirkulasi udara, rambatan suhu udara, siklon tropis, konvergensi dan parameter cuaca lainya. Akan sangat memudahkan jika proses prakiraan cuaca dapat dibantu dengan adanya aplikasi/perangkat lunak. Untuk membuat suatu aplikasi komputer ini dibutukhan software khusus pembuat program/aplikasi, seperti software yaitu Visual Basic.

Salah satu keunggulan Visual Basic adalah dapat berinteraksi dengan aplikasi lain di dalam sistem operasi Windows, memungkinkan pengguna untuk memanggil dan menggunakan semua model data yang ada di dalam sistem operasi Windows. Visual Basic 6.0 sebetulnya perkembangan dari versi sebelumnya dengan penambahan komponen yang sedang tren saat ini, seperti kemampuan pemrograman internet dan beberapa penambahan fitur database dan multimedia yang semakin baik

Penelitian ini bertujuan untuk Membuat program aplikasi prakiraan cuaca menggunakan software pembuat program yaitu Visual Basic 6.0. berdasarkan kriteria-kriteria cuaca yang digunakan oleh para prakirawan; Memilih data-data pengamatan dan model-model prakiraan cuaca yang tepat dalam membuat prakiraan cuaca.

Manfaat dari adanya aplikasi prakiraan cuaca ini maka para prakirawan dapat dengan mudah menganalisa data untuk membuat prakiraan cuaca karena aplikasi dapat dijalankan dan ditampilkan di monitor komputer. Memudahkan pengguna aplikasi untuk dapat memodifikasi setiap parameter cuaca sesuai dengan data yang tersedia. Selain itu kesalahan dalam prakiraan cuaca dapat diminimalisir.

\section{Metode}

Untuk mendapatkan kriteria mana yang sesuai dengan keadaan cuaca yang terjadi, seperti hujan, berawan, cerah dan hujan disertai petir maka diuji dengan data keadaan cuaca yang sebenarnya terjadi. Setelah mendapat kriteria yang sesuai dengan keadaan sebenarnya, kemudian dibuat tabel kriteria (Gambar 1.) yang akan digunakan untuk prakiraan cuaca.

\begin{tabular}{|c|c|c|c|c|c|c|c|c|c|c|c|c|c|c|c|c|c|c|c|c|c|c|c|c|c|c|c|c|}
\hline \multirow{2}{*}{ No } & \multirow{2}{*}{ Kriteria Cuaca } & \multicolumn{16}{|c|}{ Prakiraan Dengan Tekanan Udara, Suhu Udara dan Citra Satelit } & \multicolumn{11}{|c|}{ Model Prakiraan } \\
\hline & & P1A & & P2A & P2B & s & A & $\mathrm{T1}$ & T2 & $\mathrm{T3}$ & T44 & $\mid \mathrm{TC1}$ & \begin{tabular}{l|l|l} 
TC2 & TC \\
\end{tabular} & TC3 & $\begin{array}{lll}\text { PL1 } & \text { P } \\
\end{array}$ & 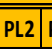 & PL3 & \begin{tabular}{l|l}
$\mathrm{K} 1$ & \\
\end{tabular} & K2 & K3 & VT1 & & & & \begin{tabular}{l|l|l}
$C P 1$ & $C P$ \\
\end{tabular} & \begin{tabular}{l|l|l|l|}
2 & CPS \\
\end{tabular} & \begin{tabular}{l|l|l}
3 & $\mathrm{RH} 1$ \\
\end{tabular} & $1 \overline{\mathrm{RH} 2}$ \\
\hline 1 & Hujan Disertai Petir & $x$ & & 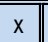 & & $\bar{x}$ & & $x$ & & $\mathrm{x}$ & & $\bar{x}$ & & & $\overline{\mathrm{x}}$ & & & $\bar{x}$ & & & 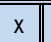 & & & $\bar{x}$ & & $\bar{c}$ & $x$ & \\
\hline \multirow{4}{*}{2} & \multirow{4}{*}{ Hujan } & $x$ & & $x$ & & $x$ & & $x$ & & $\mathrm{x}$ & & & $x$ & & $x$ & & & $x$ & & & $x$ & & & $\mathrm{x}$ & $\mathrm{x}$ & & $x$ & \\
\hline & & $x$ & & & $x$ & $x$ & & $x$ & & $x$ & & $x$ & & & $x$ & & & & $x$ & & $x$ & & & $x$ & & $x$ & $x$ & \\
\hline & & & $x$ & $x$ & & $x$ & & & $x$ & $x$ & & $x$ & & & $x$ & & & $\mathrm{x}$ & & & $x$ & & & $x$ & $\mathrm{x}$ & & $\mathrm{x}$ & \\
\hline & & $x$ & & & $x$ & $x$ & & $x$ & & \begin{tabular}{|l|}
$x$ \\
\end{tabular} & & $x$ & & & & $x$ & & & & \begin{tabular}{|l||}
$x$ \\
\end{tabular} & $x$ & & & $x$ & & $x$ & $x$ & \\
\hline \multirow{2}{*}{3} & \multirow{2}{*}{ Cerah } & & $x$ & & $x$ & & $x$ & & $x$ & & $x$ & & & $x$ & & & $x$ & & & \begin{tabular}{|l|}
$x$ \\
\end{tabular} & & $x$ & $x$ & & $x$ & & & $x$ \\
\hline & & & $x$ & & $x$ & & $x$ & $x$ & & $x$ & & & & $x$ & & $x$ & & & $x$ & & & $x$ & & $\mathrm{x}$ & $x$ & & & $x$ \\
\hline \multirow{6}{*}{4} & \multirow{6}{*}{ Berawan } & & $x$ & $x$ & & & $x$ & $x$ & & & $x$ & & $x$ & & & & $x$ & & & \begin{tabular}{|l||}
$x$ \\
\end{tabular} & & $x$ & & $x$ & & $x$ & & $x$ \\
\hline & & $x$ & & & $x$ & & $x$ & & $x$ & & $x$ & & & $x$ & & $x$ & & & $\mathrm{x}$ & & $x$ & & $x$ & & & $x$ & $x$ & $x$ \\
\hline & & $x$ & & $x$ & & & $x$ & $x$ & & $x$ & & & & $x$ & & & $x$ & & $x$ & & & $x$ & $x$ & & $x$ & $x$ & & $x$ \\
\hline & & & $x$ & & $x$ & & $x$ & & $x$ & & $x$ & $x$ & & & $x$ & & & \begin{tabular}{|l|}
$x$ \\
\end{tabular} & & & & \begin{tabular}{|l|}
$x$ \\
\end{tabular} & $x$ & & & $x$ & $x$ & $x$ \\
\hline & & & $x$ & $x$ & & & $x$ & & $x$ & $x$ & & & & $x$ & & $x$ & & & $\mathrm{x}$ & & $x$ & & $x$ & & $x$ & & $x$ & \\
\hline & & & $x$ & & $x$ & $x$ & & & $x$ & & $x$ & & $x$ & & & $x$ & & & & $x$ & & $x$ & $x$ & & $x$ & & $x$ & \\
\hline
\end{tabular}

Gambar 1. Tabel kriteria prakiraan cuaca

*Corresponding author: Jurusan Kimia FMIPA UNSRAT, Jl. Kampus Unsrat, Manado, Indonesia 95115; Email address: ricky.aror@bmkg.go.id 
Adapun logika pengerjaan program dapat di lihat pada Gambar 2.

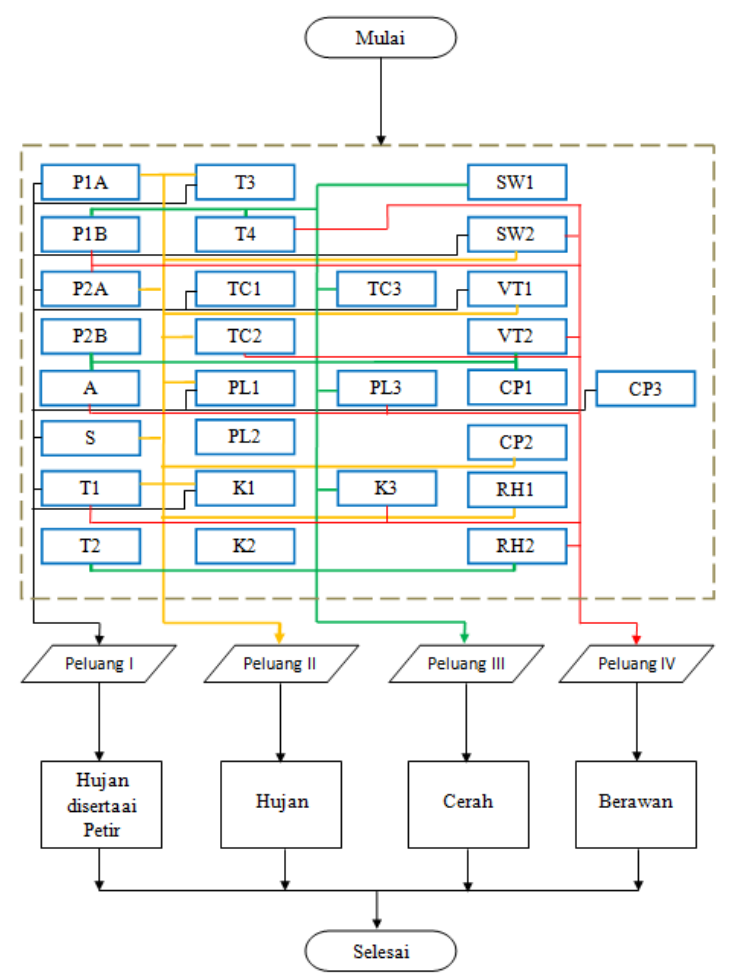

Gambar 2. Logika Pengerjaan Program

Memanfaatkan software pembuat program komputer, Visual Basic 6.0, data parameterparameter cuaca kemudian dimasukan pada program yang akan dibuat. Setelah semua parameter cuaca sudah dimasukan pada form, kemudian kode-kode perintah akan diisi pada window yang sudah disiapkan. Setelah semua kode sudah dimasukan, program tersebut kemudian diuji. Jika masih ada error (kesalahan), maka kode yang sudah dimasukan perlu diperiksa kembali. Setelah semua kode sudah benar, pengujian dilakukan lagi. Jika sudah bisa dijalankan, program tersebut kemudian di simpan sebagai file program berekstensi *.exe.

\section{Hasil dan Pembahasan}

\subsection{Persiapan}

Menyiapkan project untuk membuat program baru. Gambar 3 merupakan tampilan awal dari Microsoft Visual Basic 6.0.

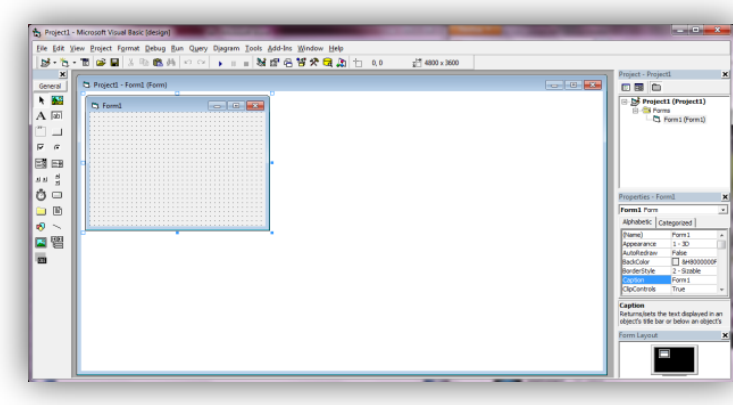

Gambar 3. Tampilan awal dari Microsoft Visual Basic 6.0

Memasukan beberapa komponen dalam toolbox seperti Text, Frame, Command, Option serta Label, dan ditata sehingga hasil formnya seperti Gambar 4.

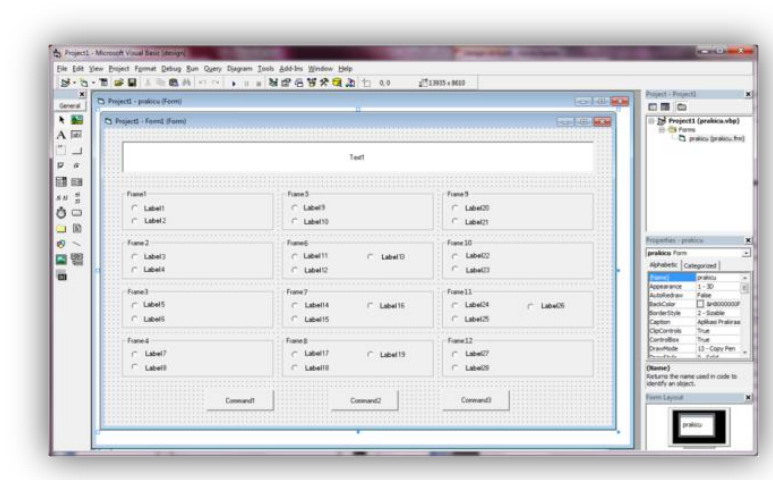

Gambar 4. Hasil tampilan form sementara

\subsection{Pengaturan Property}

Property untuk masing-masing komponen disesuaikan sehingga tampilan program menjadi:

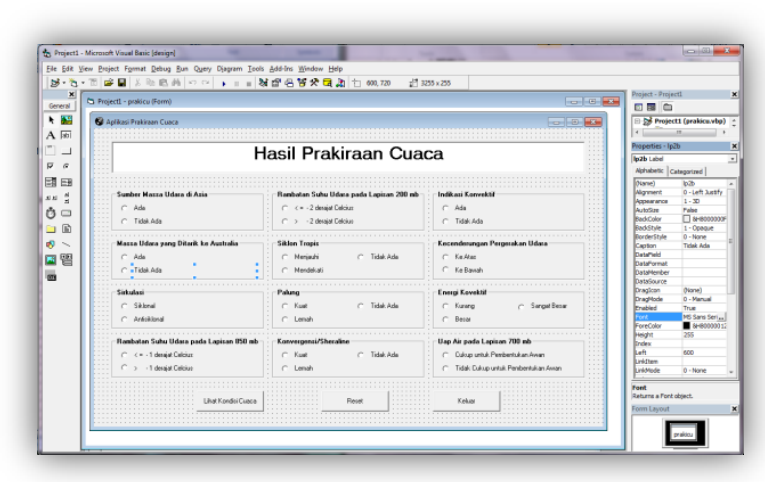

Gambar 5. Tampilan form program setelah semua properti disesuaikan 


\subsection{Pengisian Kode Program}

Dilanjutkan dengan pengisian kode pada jendela “(code)" dengan mengetikan script seperti:

Private Sub Ikc_Click()

If $\mathrm{p} 1 \mathrm{a}=$ True And $\mathrm{p} 2 \mathrm{a}=$ True And $\mathrm{s}=$ True And $\mathrm{t} 1$ $=$ True And $\mathrm{t} 3=$ True And tc1 $=$ True And pl1 = True And $\mathrm{k} 1=$ True And vt1 = True And sw2 = True And $\mathrm{cp} 3=$ True And rh1 = True Then hpc. Text $=$ "Hujan Disertai Petir" MsgBox "Hujan Disertai Petir"

artinya bahwa jika kita memilih "Ada sumber massa udara di Asia (p1a)", "Ada massa udara yang ditarik ke Australia (p2a)", "Siklonal (s)", "Rambatan suhu udara pada lapisan $850 \mathrm{mb}$ mencapai $\leq-1^{\circ} \mathrm{C}$ (t1)", "Rambatan suhu udara pada lapisan $200 \mathrm{mb}$ mencapai $\leq-2^{\circ} \mathrm{C}$ (t3)", "Ada siklon tropis tapi menjauhi daerah prakiraan (tc1)”, "Ada palung kuat di sekitar daerah prakiraan (pl1)", "Ada konvergensi (k1)", "Ada indikasi konvektif (sw2)", "Udara Cenderung bergerak ke atas (vt1)", "Energi konvektif sangat besar (cp3)", "Uap air pada ketinggian 700 mb cukup membentuk awan (rh1)", maka ketika tombol "Lihat Kondisi Cuaca" di klik maka akan tampil teks dan pesan kotak (message box) bertuliskan "Hujan Disertai Petir”.

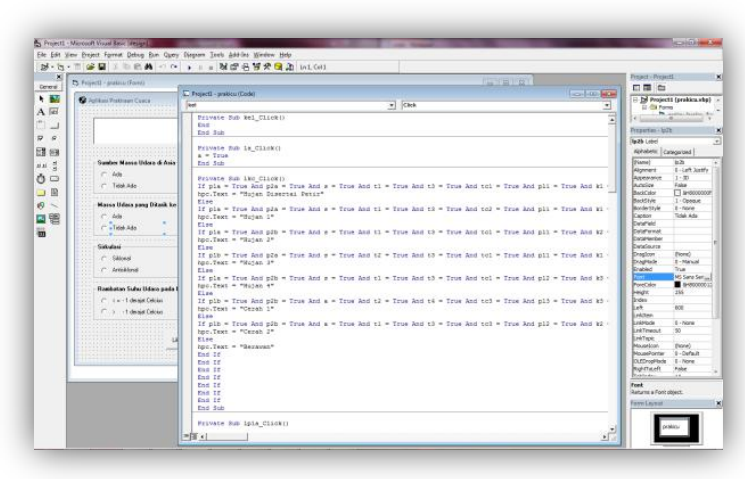

Gambar 6. Pengisian kode

\subsection{Pengujian dan Pembuatan Program Berekstensi *.exe}

Pengujian program dapat dijalankan dengan menekan shortcut pada keyboard, "F5", sehingga muncul window seperti pada Gambar 7.

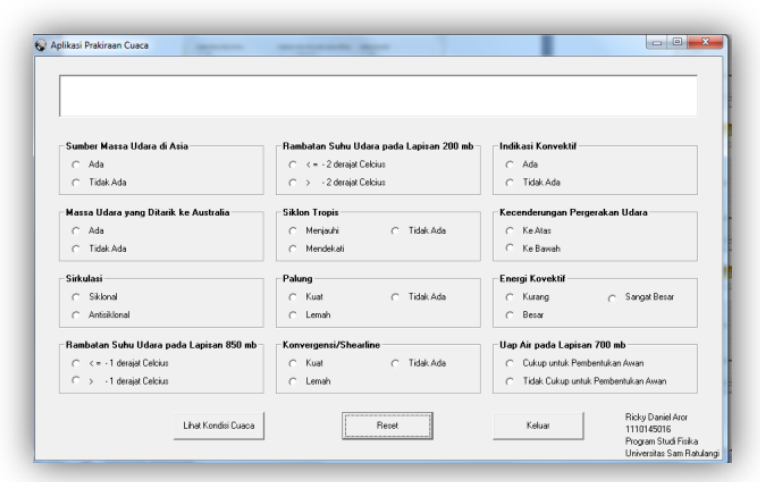

Gambar 7. Tampilan Awal Program
Pembuatan program dilanjutkan dengan memilih menu "File" kemudian klik "Make prakicu.exe" seperti Gambar 8.

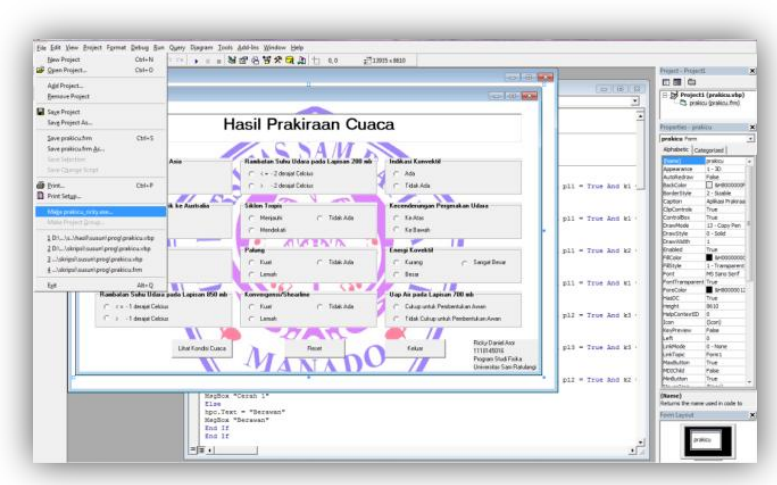

Gambar 8. Pembuatan "prakicu.exe”

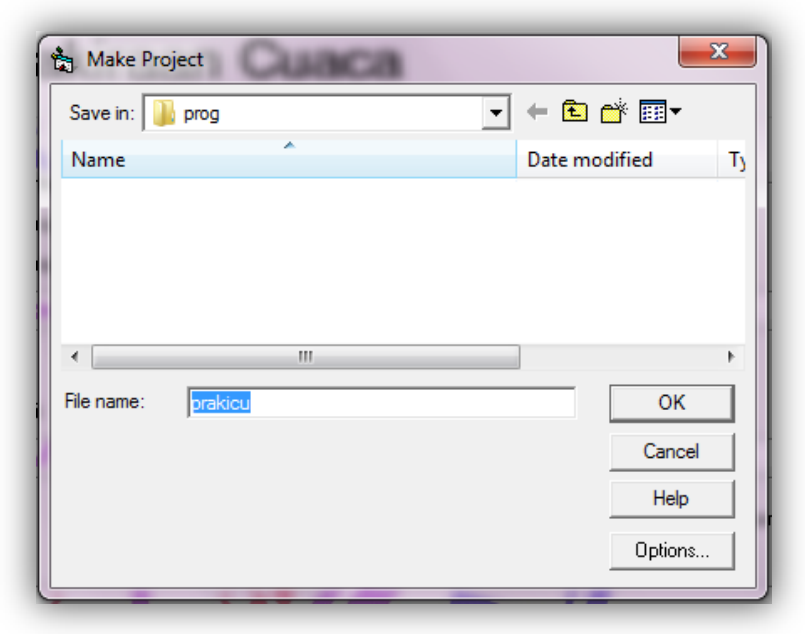

Gambar 9. Make Project Windows

Kemudian akan muncul windows seperti Gambar 9. dan klik "OK”. Program/Aplikasi "prakicu.exe" telah terbentuk. Program tersebut dapat ditemukan di directory penyimpanan yang sudah kita alamatkan sebagai penyimpanan program.

\section{Kesimpulan}

Dari penelitian ini dapat disimpulkan beberapa hal saperti berikut:

1. Data yang digunakan dalam pembuatan aplikasi prakiraan cuaca ini yaitu data tekanan udara, angin, suhu udara, trayektori siklon tropis, konvergensi, vortisitas, CAPE dan kelembaban udara.

2. Aplikasi prakiraan cuaca ini berisi pilihan-pilihan kombinasi yang mudah dimodifikasi jika terjadi kesalahan.

3. Cara menggunakan aplikasi ini yaitu dengan cara memilih parameter cuaca yang dianggap sesuai, dan kemudian dengan meng-click tombol "Lihat Konsisi Cuaca" maka akan ditampilkan hasil prakiraannya. 


\section{Daftar Pustaka}

Basuki, A. 2006. Algoritma Pemrograman 2 Menggunakan Visual Basic 6.0. Institut Teknologi Sepuluh November, Surabaya.

Bianca, B. 2009. Weather. Carlsen Verlag, Hamburg.

Davis, H. 1998. Visual Basic 6 Secrets. International Data Group Company, Califonia.

Halvorson, M. 1999. Microsoft Visual Basic 6.0 Professional, Step by Step. Microsoft Press, Washington.

Meischner, P. 2004. Weather Radar: Principles and Advanced Application. Springer-Verleg, Berlin.
Moldwin, M. 2008. An Introducton to Space Weather. Cambridge University Press, New York.

Nichole, S. 2001. Weather. Marshall Publishing, London.

Shipman, Wilson, dan Todd. 2009. An Introduction to Physical Science. Houghton Mifflin Company, California.

Zakir, A. 2005. Analisis dan Pengembangan Sistem Metode Prakiraan Cuaca di Bidang Informasi Meteorologi. Universitas Gunadarma, Bekasi. 